\title{
Facial Spinulate Demodicosis
}

\author{
Ahmed Zahr Allayali (D) \\ Department of Internal Medicine, Umm \\ Al-Qura University, Makkah, Saudi Arabia
}

\begin{abstract}
Hyperkeratotic spicules are rare cutaneous lesions associated with underlying systemic illnesses. In more recent times, facial spinulate demodicosis has been suggested as an etiological factor. Demodicosis is a common dermatological condition characterized by the presence of Demodex mites in the pilocutaneous follicles. This report describes the case of a 40-year-old otherwise healthy woman who reported having undetected facial follicular spicules as a result of demodicosis. The diagnosis was confirmed by physical examination and skin punch biopsy. Initial treatment with 5\% permethrin did not resolve the rash. As such, $1 \%$ Ivermectin was prescribed, after which the rash resolved completely within 3 weeks.
\end{abstract}

Keywords: spinulate, Demodex folliculorum, demodicosis

\section{Introduction}

Hyperkeratotic spicules are relatively uncommon cutaneous lesions caused by various underlying pathologies, such as hypovitaminosis $\mathrm{A},{ }^{1}$ chronic renal failure, ${ }^{2}$ lymphoma, Crohn's disease, ${ }^{3}$ monoclonal gammopathy, or other malignancies. ${ }^{4}$ Owing to their diverse clinical presentation, hyperkeratotic spicules have been given multiple names, including filiform hyperkeratosis ${ }^{5}$ and viralassociated trichodysplasia. ${ }^{6,7}$ Since these lesions are rare and can present with a variable clinical picture when coexisting with a systemic illness; as such, a definite etiology is not available. The characteristic appearance of a hyperkeratotic spicule is a confined area of hyperkeratosis with a column of keratotic material extending from the stratum corneum. ${ }^{8}$ The digitate keratoses represent a group of inherited and acquired conditions. The word digitate is used to define a minute fingerlike projection. In the current literature, a range of terms are used when describing digitate keratoses. These include "acuminate," "aggregate," "conical," "filiform," "music box spine," "spiked", and "spiny." As such, there is no distinct definition of the form digitate keratoses take. Digitate keratoses, in itself, is described using a variety of terms, including arsenical keratosis, multiple filiform verrucae, postirradiation digitate keratosis, spiny keratoderma, phrynoderma, hyperkeratotic spicules, trichodysplasia spinulosa, minute digitate hyperkeratosis, and multiple lichen spinulosus. Furthermore, digitate keratoses can be divided into two subgroups: localized and generalized. ${ }^{9}$

The term demodicosis describes a group of cutaneous illnesses caused by Demodex mites (natural commensals that live in the hair follicles). Facial spinulate demodicosis, which is also referred to as pityriasis folliculorum, describes the development of Demodex mites in high numbers within the pilocutaneous follicles of the face. Facial infestation of Demodex folliculorum is common and has recently
Correspondence: Ahmed Zahr Allayali Department of Internal Medicine, Umm Al-Qura University, Makkah, Saudi Arabia Tel +96653004I029

Email ahmedz98@hotmail.com 
been added to the list of systemic illnesses that lead to the development of hyperkeratotic spicules. ${ }^{10}$ However, the condition remains largely undiagnosed as it is generally found in otherwise healthy individuals. This paper describes the case of a healthy middle-aged woman who had undetected facial follicular spicules as a result of Demodicosis. Despite two years of treatment for her condition, no remedy had been found.

\section{Case Report}

A 40-year-old woman presented to the JC Dermatology Clinic, Jeddah, Saudi Arabia, with a 24-month history of dryness/roughness around the right jawline and lower right cheek. The patient had previously sought medical assistance from several doctors and received multiple topical treatments (metronidazole gel, pimecrolimus, and urea-containing moisturizers); however, the situation had not improved.

The patient reported with dry skin with numerous follicular hyperkeratotic spicules with a rough consistency in the anterior aspect of the right jaw and across the midzone that could be palpated on physical examination (Figure 1). During the two years of prior treatment, no skin biopsy had been performed, and the treatment plan had followed that typically prescribed for rosacea, ie, topical drugs. However, this had only slightly improved the patient's condition. Therefore, we performed a skin punch biopsy and sent the tissue for pathological analysis. A histological inspection of the tissue specimen revealed that the epidermis contained noticeable hair follicle dilatation and numerous Demodex mites extruding from the surface surrounded by a ring of dense homogeneous eosinophilic hyperkeratotic material.

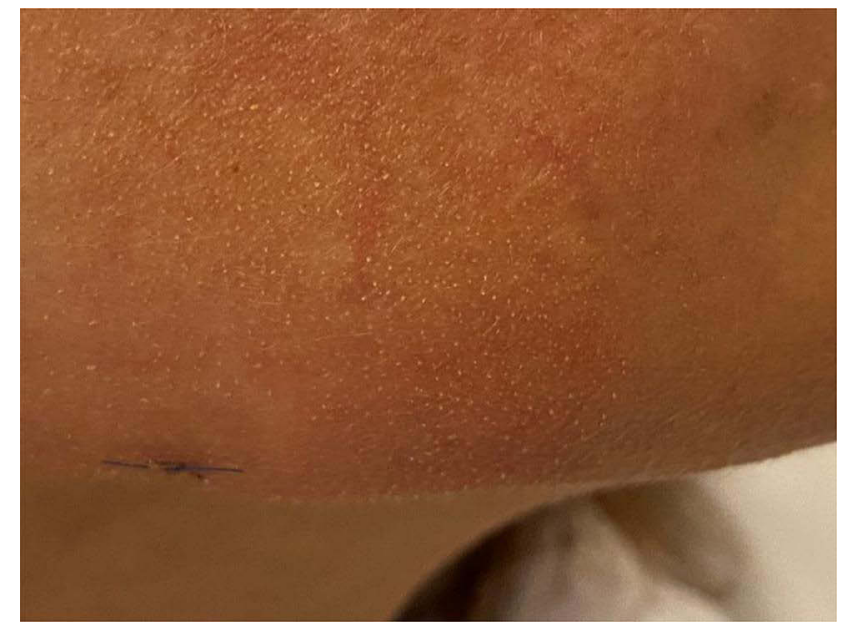

Figure I Facial follicular hyperkeratotic spicules on right anterior jaw line.

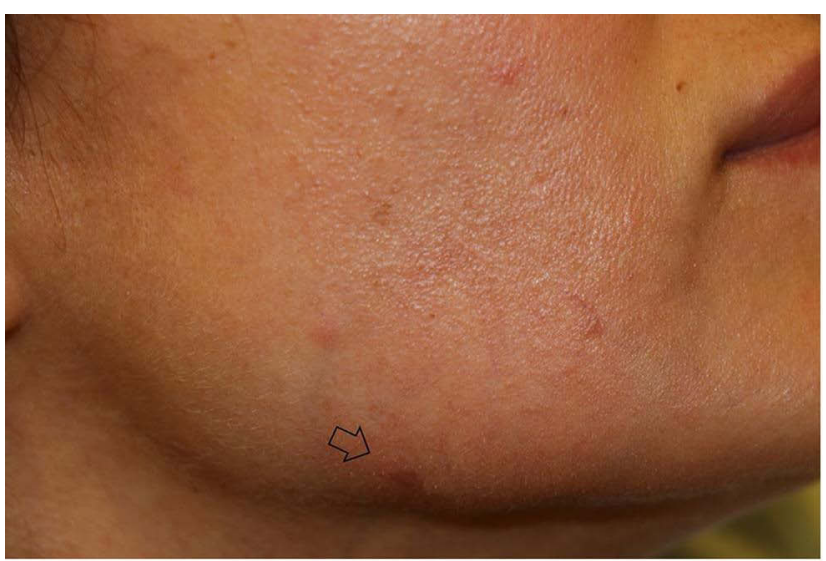

Figure 2 Facial follicular hyperkeratotic spicules after three weeks of treatment with $5 \%$ permethrin.

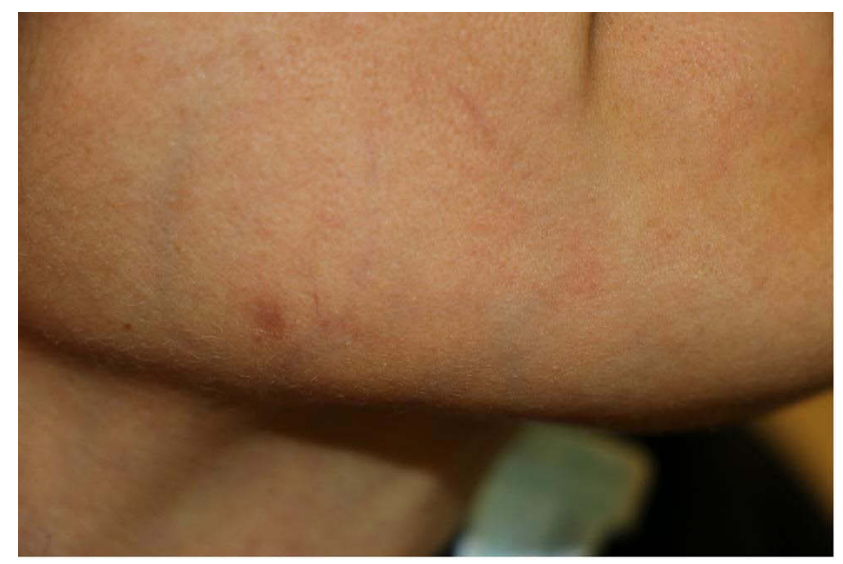

Figure 3 Fully resolved follicular hyperkeratotic spicules after treatment with $1 \%$ Ivermectin cream for three weeks.

The patient was initially prescribed a topical application of 5\% Permethrin cream twice daily; however, a three-week follow-up examination revealed only $70 \%$ improvement with evident follicular spicules (Figure 2). As a result, the treatment approach was modified to $1 \%$ Ivermectin cream (Soolantra) twice daily. The next threeweek follow-up revealed that the follicular spicules had cleared entirely (Figure 3).

\section{Discussion}

Demodex mites are common ectoparasites carried by mammals. Of the various species of Demodex, D. brevis and $D$ folliculorum are the only ones found on human skin. ${ }^{11}$ Notably, the age of the host human determines the distribution of Demodex mites in normal human hair follicles. ${ }^{12,13}$ Chen et al ${ }^{14}$ clinically classified demodicosis as primary or secondary. Primary demodicosis refers to the lesions that occur in people who do not have an underlying 
systemic illness that may impact innate immunity resulting in a reduced normal commensal activity, while secondary demodicosis occurs in individuals with a systemic condition leading to immunosuppression or a history of inflammatory dermatosis. Chronic renal failure, phototherapy, calcineurin inhibitors, topical glucocorticoids, and treatment with epidermal growth-factor-receptor inhibitors are all potential causes of secondary demodicosis. ${ }^{15,16}$

Ayres and Ayres ${ }^{16}$ documented two types of cutaneous lesions linked with D. folliculorum. One of these was frequently observed in middle-aged and elderly females who used a lot of make-up powder and/or cream but rarely used soap to clean their faces. The most prevalent symptoms of dermal eruptions were diffuse face erythema, dry skin, a rough look with follicular scaling, and a feeling of "skin burning or itching." This combination of symptoms is frequently referred to as "Pityriasis folliculorum." The second variant was symptomatically similar to the first; however, additional rosacea-like lesions were observed. ${ }^{17}$ Dominey et $\mathrm{al}^{17}$ further described pityriasis folliculorum in six patients who reported "irritation or burning" in the affected areas. Notably, each patient stated that they only used soap and water to wash their faces every day, and they did not apply any heavy make-up oil or cream. During palpation, the skin had a sandpaper-like texture, homogeneous erythema, and blocked follicular orifices. $^{17}$

In other studies, where the patient was receiving hydroxyurea for polycythemia, such as Faria et $\mathrm{al}^{10}$ and Boutli et al, $^{12}$ no topical therapy worked for facial Demodex spinulosis until the patient stopped taking hydroxyurea. Fariña et $\mathrm{al}^{10}$ reported a positive response to the prescription of $1 \%$ permethrin in their patient. Tamer et al ${ }^{15}$ also recorded a case of Demodex mite infestation with hyperkeratotic follicular spicules emerging from the trunk, neck, and face that responded to treatment.

Certain alternative hyperkeratotic spicular lesions may mimic the lesions observed in cases of demodicosis. Trager et $\mathrm{al}^{18}$ reported on four individuals with follicular mucinosis of the neck and head, which were similar to folliculotropic mycosis fungoid. Likewise, Tomasini et al ${ }^{19,20}$ described a subgroup of follicular mycosis fungoides that mimic numerous follicular disorders. These lesions were spiky and/or keratosis-pilaris-like that represented the primary, and almost predominant, clinical manifestation of the fungoides; however, these lesions had a favorable prognosis. Other rare clinical findings of folliculotropic mycosis fungoides were described by Mitteldorf et $\mathrm{al}^{21}$ to include follicular hyperkeratosis, referred to as "spikes," which are an early sign of folliculotropic mycosis fungoides. In 1944, Heidenström et $\mathrm{al}^{4}$ described follicular hyperkeratotic spicules as a rare, but highly characteristic, dermatosis that is associated with multiple myeloma. Subsequently, Tomasini et $\mathrm{al}^{22}$ described eruptive ulcerative follicular spicules heralding the progression of active multiple myeloma. Another entity, the case of multiple minute digitate hyperkeratoses, was described by Caccetta et al. ${ }^{9}$ Multiple minute digitate hyperkeratoses is predominantly a non-follicular digitate keratosis affecting the trunk and the limbs, while the face and palmoplantar surfaces are not affected.

The patient in the current case report was in good health and did not wear heavy make-up on a regular basis. She cleansed her face daily with soap and water. A complete resolution of the condition was achieved only after using topical Ivermectin. Lichen spinulosis and numerous minute digitate hyperkeratosis are two additional disorders linked to spinulosis-the former affects the face, while the latter has spicule development but no follicular involvement. Since lichen spinulosis is an uncommon variety of dermatosis with an unknown origin, the majority of researchers regard it as a clinically distinct form of keratosis pilaris. The most common symptoms of this illness are follicular papules with a keratotic horny spine gathered in large patches symmetrically throughout the extensor surfaces of the neck, face, trunk, and limbs. ${ }^{23,24}$ These lesions present in the form of dilated follicular infundibula packed with keratotic plugs as visualized on microscopic inspection. Lichen spinulosis-like lesions have been identified in miliary papular syphilis, lymphoproliferative diseases, seborrheic dermatitis, and individuals who have received thallium, arsphenamine, gold thiosulphate, or those who are HIV positive or have acne conglobate. ${ }^{25,26}$

To summarize, this report describes a case of facial follicular spinulosis that was discovered during a physical examination and verified by a skin biopsy, which revealed a large number of follicular mites. The fact that the first treatment with 5\% Permethrin creams only partially removed the spicules further corroborates the pathogenic action of Demodex mites. However, a subsequent application of $1 \%$ Ivermectin cream removed the rash completely.

In conclusion, Pityriasis folliculorum caused by Demodex mites is a common dermatological condition that many dermatologists are not familiar with; hence, the condition is often misdiagnosed or undiagnosed. The present case study adds to the growing body of evidence 
for demodicosis by highlighting its importance in the differential diagnosis of facial eruptions in the form of follicular spicules.

\section{Consent for Photos and Publication and Institutional Approval}

The patient provided written consent for photos and publication of the details of her case on the condition of anonymity. Institutional approval was not required to publish the case.

\section{Disclosure}

The author reports no conflicts of interest in this work.

\section{References}

1. Loewenthal LJA. A new cutaneous manifestation in the syndrome of vitamin a deficiency. Arch Derm Syphilol. 1933;28(5):700-708. doi:10.1001/archderm.1933.01460050094008

2. Ostlere LS, Ashrafzadeh P, Harris D, Rustin MHA. Response of uremic follicular hyperkeratosis to peritoneal dialysis. J Am Acad Dermatol. 1992;26(5):782-783. doi:10.1016/j.jaad.2008.10.058

3. Aloi FG, Molinero A, Pippione M. Parakeratotic horns in a patient with crohn's disease. Clin Exp Dermatol. 1989;14(1):79-81. doi:10.1111/j.1365-2230.1989.tb00892.x

4. Heidenström N, Tottie M. Haut und Gelenkveränderungen bei multiplem Myelom. Acta Derm Venereol. 1944;24:192-201.

5. Kaddu S, Peter Soyer H, Kerl H. Palmar filiform hyperkeratosis: a new paraneoplastic syndrome? J Am Acad Dermatol. 1995;33 (2):337-340. doi:10.1016/0190-9622(95)91429-3

6. Wanat KA, Holler PD, Dentchev T, et al. Viral-associated trichodysplasia: characterization of a novel polyomavirus infection with therapeutic insights. Arch Dermatol. 2012;148(2):219-223. doi:10.1001/ archdermatol.2011.1413

7. Matthews MR, Wang RC, Reddick RL, Saldivar VA, Browning JC. Viral-associated trichodysplasia spinulosa: a case with electron microscopic and molecular detection of the trichodysplasia spinulosa-associated human polyomavirus. J Cutan Pathol. 2011;38 (5):420-431. doi:10.1111/j.1600-0560.2010.01664.x

8. Zarour H, Grob JJ, Andrac L, Bonerandi JJ. Palmoplantar orthokeratotic filiform hyperkeratosis in a patient with associated darier's disease. Dermatology. 1992;185(3):205-209. doi:10.1159/000247448

9. Caccetta TP, Dessauvagie B, McCallum D, Kumarasinghe SP. Multiple minute digitate hyperkeratosis: a proposed algorithm for the digitate keratoses. J Am Acad Dermatol. 2012;67(1):e49-e55. doi:10.1016/j.jaad.2010.07.023

10. Fariña MC, Requena L, Sarasa JL, et al. Spinulosis of the face as a manifestation of demodicidosis. $\mathrm{Br} \quad J$ Dermatol. 1998;138 (5):901-903. doi:10.1046/j.1365-2133.1998.02234.x

Clinical, Cosmetic and Investigational Dermatology

\section{Publish your work in this journal}

Clinical, Cosmetic and Investigational Dermatology is an international, peer-reviewed, open access, online journal that focuses on the latest clinical and experimental research in all aspects of skin disease and cosmetic interventions. This journal is indexed on CAS.
11. Hsu C, Hsu MM, Lee JY. Demodicosis: a clinicopathological study. $J$ Am Acad Dermatol. 2009;60(3):453-462. doi:10.1016/j. jaad.2008.10.058

12. Boutli F, Delli FS, Mourellou O. Demodicidosis as spinulosis of the face - a therapeutic challenge [19]. J Eur Acad Dermatology Venereol. 2007;21(2):273-274. doi:10.1111/j.14683083.2006.01844.x

13. Kim HS, Yu DS, Kim JW. Demodicidosis as spinulosis of the face a therapeutic challenge. J Eur Acad Dermatology Venereol. 2007;21 (2):272-273. doi:10.1111/j.1468-3083.2006.01843.x

14. Chen W, Plewig G. Human demodicosis: revisit and a proposed classification. Br J Dermatol. 2014;170(6):1219-1225. doi:10.1111/ bjd. 12850

15. Tamer F, Sarifakioglu E, Orenay OM. A rare clinical manifestation of spinulate demodicosis. Dermatol Online J. 2016;22(11):13030/ qt4qz335gw.

16. Ayres S. Demodectic Eruptions (Demodicidosis) in the human: 30 years' experience with 2 commonly unrecognized entities: pityriasis Folliculorum (Demodex) and Acne Rosacea (Demodex type). Arch Dermatol. 1961;83(5):816. doi:10.1001/archderm.1961.01580110104016

17. Dominey A, Tschen J, Rosen T, Batres E, Stern JK. Pityriasis folliculorum revisited. J Am Acad Dermatol. 1989;21(1):81-84. doi:10.1016/S0190-9622(89)70152-3

18. Trager MH, Queen D, Chen D, Hodak E, Geskin LJ. Demodexinduced follicular mucinosis of the head and neck mimicking folliculotropic mycosis fungoides. JAAD Case Rep. 2020;6(4):266-272. doi:10.1016/j.jdcr.2020.01.014

19. Tomasini C, Michelerio A, Quaglino P. Spiky/keratosis-pilaris-like early follicular mycosis fungoides: a clinicopathologic study of 20 cases with extended follow-up. $J$ Cutan Pathol. 2021;48 (9):1124-1132. doi:10.1111/cup.14002

20. Tomasini C, Kempf W, Novelli M, et al. Spiky follicular MYCOSIS FUNGOIDES: a clinicopathologic study of 8 cases. J Cutan Pathol. 2015;42(3):164-172. doi:10.1111/cup.12399

21. Mitteldorf C, Stadler R, Sander CA, Kempf W. Folliculotropic mycosis fungoides. $J$ Dtsch Dermatol Ges. 2018;16(5):543-557. doi: $10.1111 /$ ddg. 13514

22. Tomasini C, Michelerio A, Brazzelli V. Eruptive ulcerative follicular spicules heralding progression of smoldering multiple myeloma. J Cutan Pathol. 2019;46(11):844-851. doi:10.1111/cup.13523

23. Boyd AS. Lichen spinulosus: case report and overview. Cutis. 1989;43(6):557-560.

24. Friedman SJ. Lichen spinulosus: clinicopathologic review of thirty-five cases. J Am Acad Dermatol. 1990;22(2):261-264. doi:10.1016/0190-9622(90)70035-G

25. Cohen SJ, Dicken CH. Generalized lichen spinulosus in an HIV-positive man. J Am Acad Dermatol. 1991;25(1):116-118. doi:10.1016/S0190-9622(08)80503-8

26. Resnick SD, Murrell DF, Woosley J. Acne conglobata and a generalized lichen spinulosus-like eruption in a man seropositive for human immunodeficiency virus. J Am Acad Dermatol. 1992;26 (6):1013-1014. doi:10.1016/S0190-9622(08)80345-3
The manuscript management system is completely online and includes a very quick and fair peer-review system, which is all easy to use. Visit http://www.dovepress.com/testimonials.php to read real quotes from published authors.

\section{Dovepress}

